\title{
Estrategia de desarrollo local sustentable en el Área Natural Protegida Parque Otomí-Mexica del Estado de México. Circuitos turísticos en el municipio de Isidro Fabela.
}

\author{
Daniel Villegas Martínez* Jesús Gastón Gutiérrez Cedillo** \\ José Isabel Juan Pérez***
}

Universidad Autónoma del Estado de Mexico (Mexico)

\begin{abstract}
Resumen: El objeto de estudio de la presente investigación se basa en el análisis realizado al diseño, instrumentación y evaluación de circuitos turísticos fundamentados en una propuesta de base comunitaria, sustentada en el enfoque del turismo rural y el desarrollo local sustentable. La estructura metodológica formulada y aplicada en esta investigación incluye la planeación participativa, aplicación de entrevistas estructuradas, observación directa en campo; la aplicación conjunta de herramientas de sistemas de información geográfica, el análisis multicriterio y la cartografía participativa. Como resultado se propone que la manera más viable y sustentable de aprovechar los recursos del territorio municipal de Isidro Fabela desde una perspectiva local, es mediante la instrumentación de circuitos turísticos que promuevan el desarrollo de actividades relacionadas con el turismo rural. La evaluación de los circuitos se realizó mediante la colaboración y el conocimiento de los habitantes y autoridades locales, estudiantes y académicos universitarios, basada en las preferencias de los visitantes, quienes determinaron que cinco de los ocho circuitos turísticos diseñados resultan ser viables para su instrumentación.
\end{abstract}

Palabras Clave: Circuitos turísticos; Desarrollo local sustentable; Estrategia; Evaluación; Instrumentación; Planeación participativa.

Sustainable local development strategy in the Otomí-Mexica Natural Protected Area of the State of Mexico. Touristic circuits at the municipality of Isidro Fabela.

Abstract: The object of study of this research is based on the analysis carried out on the design, instrumentation and evaluation of tourist circuits based on a community-based proposal, based on the approach of rural tourism and sustainable local development. The methodological structure formulated and applied in this research includes participatory planning, application of structured interviews, direct observation in the field; the joint application of geographic information systems tools, multi-criteria analysis and participatory mapping. As a result, it is proposed that the most viable and sustainable way to take advantage of the resources of the municipal territory of Isidro Fabela from a local perspective is through the implementation of tourist circuits that promote the development of activities related to rural tourism. The evaluation of the circuits was made through the collaboration and knowledge of the inhabitants and local authorities, students and university academics, based on the preferences of the visitors, who determined that five of the eight touristic circuits designed are viable for their instrumentation.

Keywords: Evaluation; Instrumentation; Participatory planning; Strategy; Sustainable local development; Touristic circuits.

\footnotetext{
* Universidad Autónoma del Estado de México (México); E-mail: geo_morf@hotmail.com

** Universidad Autónoma del Estado de México (México); E-mail: ggc1321@yahoo.com.mx

*** Universidad Autónoma del Estado de México (México); E-mail: jupi582602@gmail.com
} 


\section{Introducción}

La presente investigación se desarrolló bajo las consideraciones epistemológicas del turismo rural, el desarrollo local y el desarrollo sustentable, y de la aplicación de herramientas geotecnológicas, además de destacar el rol que juegan las comunidades rurales en la propuesta, diseño e instrumentación de estrategias de desarrollo local que de manera empírica se implementan dentro de los territorios rurales de México. El vínculo que se obtuvo durante este proceso de investigación participativo (comunidad-universidad) es un intento por mejorar las estrategias de desarrollo que los habitantes y autoridades del municipio de Isidro Fabela han venido desarrollando de forma práctica sin obtener los resultados deseados.

En este artículo se analiza de forma crítica las propuestas que los habitantes y autoridades locales tienen pensado desarrollar, las opiniones que se manifiestan al interior del municipio son expresadas principalmente por aquellas personas y autoridades que se encuentran vinculadas estrechamente con el desarrollo de actividades sociales, ambientales y turísticas. Actividades que les han permitido comprender la importancia de generar e instrumentar estrategias que mejoren el bienestar de los habitantes sin poner en riesgo los recursos naturales y socioculturales disponibles en el territorio.

Desde estas experiencias surgen algunos conocimientos que les han ayudado a comprender los problemas de rezago social, económicos, educativos y de salud por los que actualmente atraviesa el $94.77 \%$ de la población municipal. De acuerdo al Programa de Desarrollo Municipal de Isidro Fabela 2013-2015 y las estadísticas presentadas por el Consejo Nacional de Evaluación de la Política de Desarrollo Social (CONEVAL) el 43.81\% de la población municipal se encuentra en situación de pobreza, el 15.13\% en pobreza extrema, el $35.83 \%$ en pobreza moderada y sólo el $5.23 \%$ de la población está considerada fuera del rango de vulnerabilidad de pobreza y marginación (CONEVAL, 2012).

La problemática referida ha generado que más del 70\% de la población económicamente activa del municipio (PEA), se encuentre realizando actividades económicas dentro del sector terciario, siendo el comercio informal al por menor la principal actividad económica, seguida de actividades económicas relacionadas con el transporte público. A partir del análisis de esta problemática, de las inquietudes actuales de un sector de la población ( 25 habitantes) y de algunas autoridades vinculadas con el desarrollo del turismo (regidora en turismo y educación) el desarrollo social (coordinador) y del ambiente (director municipal), interesados por mejorar las condiciones económicas, ambientales y socioculturales de la población de Isidro Fabela, surge la propuesta del diseño y creación de circuitos turísticos para fomentar el aprovechamiento y conservación de los recursos naturales de la región.

Este acercamiento se realizó mediante una reunión, en la cual participaron representantes sociales, personal del Ayuntamiento del municipio y representantes de la universidad (alumnos y profesores). En esta reunión se discutieron diversos puntos con el fin de escuchar las inquietudes y opiniones de los representantes locales y con ello seleccionar, estructurar y definir una estrategia viable que les permita aprovechar y difundir de manera adecuada los recursos con los que cuenta su municipio. La población local afirmó en todo momento, que su territorio tiene amplia diversidad de recursos naturales, arquitectónicos, culturales e históricos que pueden ser utilizados para promover el turismo y con ello generar fuentes de empleo para los habitantes. El resultado obtenido durante la reunión fue el acuerdo para diseñar de manera participativa (ayuntamiento-universidad) una serie de circuitos turísticos con los cuales se pueda realizar un adecuado aprovechamiento del territorio.

El desarrollo e instrumentación de los circuitos turísticos fue realizado mediante una metodología participativa que consta de cinco fases de análisis. La primera describe el acercamiento de representantes de la universidad con pobladores y autoridades del Ayuntamiento para definir una estrategia de desarrollo local. En la segunda fase, se realizó una caracterización geográfica del territorio para determinar el estado actual de los componentes territoriales (biofísicos y socioculturales) del municipio. Los métodos, materiales y herramientas utilizadas en el diseño de los circuitos turísticos se describen en la tercera etapa metodológica.

En la cuarta fase de análisis se realizó una evaluación multicriterio para determinar la viabilidad de los circuitos turísticos desde una perspectiva local, administrativa y académica. En la última etapa de la metodología se explica cómo un grupo de visitantes (20 personas) evaluaron el recorrido de uno de los circuitos turísticos que resultó viable desde la evaluación multicriterio. Se concluye con una serie de reflexiones que analizan y discuten de manera crítica las limitantes y posibilidades de éxito que tienen los circuitos turísticos para ser implementados como una estrategia de desarrollo local sustentable dentro del territorio que conforma el municipio de Isidro Fabela. 


\section{Antecedentes}

Las tendencias actuales de globalización han marcado las dinámicas del territorio y la construcción de nuevos paradigmas. Dentro de lo rural, han surgido diversos enfoques y modelos de desarrollo que buscan ampliar los horizontes y las perspectivas que se tienen sobre el mundo rural y explicar las dinámicas de estos espacios y cómo ha evolucionado en las últimas décadas. La nueva ruralidad ha sido uno de ellos, la cual busca explicar las nuevas tendencias del territorio, donde la dicotomía entre lo rural y lo urbano desaparece paulatinamente (Bertrand et al., 1987).

Durante la década de 1980, México se encontraba en plena transformación de sus áreas rurales ya que el Estado comenzó una transición en su modelo de desarrollo económico, pasando del modelo benefactor a establecer un modelo neoliberal que muchos países de Europa habían adoptado, esto tuvo como consecuencia un efecto negativo en el desarrollo socioeconómico de la población que vivía en zonas rurales, pues fue ahí donde provoco fuertes problemas sociales como la disminución de empleos, lo cual ocasionó el aumento en los niveles de migración hacia las ciudades más grandes de México y los Estados Unidos de América y con ello el aumento de pobreza entre los sectores de la población que decidían quedarse en sus lugares de origen (Cooney, 2007).

Según el CONEVAL para el año 2012 se calculó que en México había alrededor de 53.3 millones de personas pobres (45.5\% del total de la población), frente a unos 52.8 millones registrados durante 2010 . Con base en el aumento de los niveles de pobreza de las zonas rurales de México, el gobierno instituyó el Fondo Nacional de Apoyo a Empresas Sociales (FONAES) reconocido como el pionero del turismo rural en México, el cual surge como una alternativa a los problemas del mundo rural desatados por el cambio de modelo económico que presentaba el país. El ahora Instituto Nacional de la Economía Social (INAE) antes FONAES, propone al turismo rural y sus diversas modalidades como una alternativa para generar ingresos extras y mejorar la calidad de vida de la población rural en México.

Según Pérez (2010), el turismo rural surge como una vertiente del turismo alternativo que se caracteriza por desarrollarse en espacios rurales y basarse en principios de aprovechamiento responsable de los entornos ambiental, sociocultural y económico de las zonas donde se lleva a cabo. Esta actividad tiene como objetivo el crecimiento económico y la revalorización de las áreas rurales, ayudando con ello a disminuir los niveles de pobreza, haciendo partícipes a los sectores más desprotegidos del mercado laboral (mujeres, jóvenes y ancianos) involucrándolos en actividades productivas del territorio.

En este sentido Garduño et al. (2009) y Varisco (2015) hacen referencia al turismo rural como una fuente de ingresos adicionales a las actividades agropecuarias que desarrollan las personas en áreas rurales, aprovechando la riqueza cultural, social y ambiental presentes en el territorio. Mencionan que este desarrollo turístico propicia que el campesino pueda generar su propia economía a través de actividades que realiza en su vida cotidiana, ofreciendo con ello servicios de interés para las personas que usualmente no están familiarizadas con estas actividades, lo que permitirá reducir los niveles de pobreza en sus comunidades.

De esta forma, el turismo rural, al tratarse de una actividad integradora se postula como uno de los principales propulsores de la valorización del territorio que contribuye eficazmente a: 1) incrementar el ingreso y el empleo rural, especialmente de jóvenes y mujeres, limitando su migración a las ciudades, problema especialmente frecuente en zonas de montaña; 2) valorizar y recuperar la arquitectura rural y el patrimonio inmobiliario tradicional; 3) redescubrir y promover los productos típicos y las maneras tradicionales de cultivarlos y prepararlos; 4) integrar la cultura campesina con la cultura artesanal (culinaria y de otros tipos); y 5) conservar el paisaje rural (Cooney, 2007).

Desde la perspectiva integral de Cooney (2007), Garduño et al. (2009), Pérez (2010) y Varisco (2015) se puede definir el turismo rural como una actividad integral que contempla entre sus objetivos el aprovechamiento de los recursos del territorio y de manera adicional integra a las actividades agropecuarias y forestales como parte de los servicios que se pueden ofertar dentro de los territorios rurales, considerando en todo momento el aprovechamiento sustentable interno y externo sobre los recursos naturales, sociales, económicos, políticos y culturales que se encuentran inmersos en el territorio, ya que estos serán los principales protagonistas del desarrollo. Como se puede apreciar los fundamentos teóricos y metodológicos del turismo rural tiene una estrecha relación con las directrices epistemológicas del desarrollo local y el desarrollo sustentable.

Para entender las relaciones entre estos conceptos y cómo dan paso al desarrollo local sustentable, es necesario considerar que durante el año 1975 el Banco Mundial expuso por primera vez el concepto de desarrollo local, modelo que a lo largo de su construcción conceptual ha plasmado sus objetivos más allá de la visión limitada del modelo tradicional capitalista actual. Surge como una opción para 
promover los proyectos de desarrollo sustentable, impulsando y potencializando los territorios locales, desde un pensamiento racional sobre el aprovechamiento de los recursos naturales, sociales, económicos, políticos y culturales que se encuentran en ellos. De acuerdo con Rofman y Villar (2006) el desarrollo local plantea una nueva forma de relacionar el ambiente con la sociedad, estos autores determinan que, si no existe la capacidad y la voluntad de equidad social que, da paso a la justicia social, difícilmente se podrá garantizar a todos los ciudadanos un acceso recíproco de alimentos, servicios de salud, educación, trabajo y empleo.

El punto medular de esta percepción recae en que la justicia social, es un elemento clave que eslabona al estado con la sociedad y por consecuencia al crecimiento económico con el desarrollo social. Sin embargo, mientras no se logren las condiciones necesarias para generar fuentes de empleo y la intervención de los sectores sociales, públicos y privados en pos de una justicia social, no es posible hablar de un desarrollo local. Por su parte Troitiño (2000) expone que en todo territorio existe una sociedad que expresa una cultura propia, la cual se forma a partir del uso de los recursos que le provee su entorno natural y que, al ser usados de una manera racional, entran en un proceso de revalorización territorial, fomentando con ello nuevas expectativas y oportunidades para el desarrollo futuro de territorios locales en donde los principales protagonistas serán el territorio, la sociedad y la cultura. Ya que a partir de sus interrelaciones se fortalecerá el bienestar integral de las sociedades y como consecuencia la sustentabilidad del territorio y sus componentes biofísicos y socioculturales.

Durante la década de 1980 la Comisión Mundial sobre Medio Ambiente y Desarrollo mediante el informe "Nuestro Futuro Común" coordinado por la doctora noruega Gro Harlem Brundtland, se propone por primera vez el término "desarrollo sustentable", concepto que centró su atención en los modelos económicos preponderantes de los países desarrollados y en los impactos negativos que estos estaban causando sobre los sistemas ecológicos acogidos en los países subdesarrollados. El término desarrollo sustentable se sustenta en los principios epistemológicos de tres disciplinas: la ecología, la economía y la sociología, las cuales buscan el desarrollo y crecimiento económico de una sociedad contemplando la conservación de los recursos naturales (Ceballos, 2010).

Para la década de 1990, el concepto de desarrollo sustentable dejó de ser un tema emergente y se convirtió en tema obligado dentro de los debates políticos y programas de gobierno a nivel mundial, fue tan grande el impacto que causó este nuevo modelo entre los países desarrollados como subdesarrollados que México trató de insertar un régimen jurídico normativo que se encargara de regular y coordinar las problemáticas ambientales, evitando con esto poner en riesgo el stock del capital natural a través de normas que promovieran la preservación del medio ambiente y los recursos naturales.

Para alcanzar la sustentabilidad localmente, es necesario lograr el desarrollo local desde una perspectiva de aprovechamiento racional y sustentable de los componentes del territorio, para lo cual el acceso a los recursos debe realizarse con equidad y justicia social. Con base en este enfoque teórico-conceptual se define el desarrollo local sustentable, el cual busca fundamentar toda acción colectiva que recaiga sobre el aprovechamiento sustentable de los territorios locales, en aras de transitar hacia escenarios locales más justos y prósperos, en donde la equidad y el desarrollo social para todos los habitantes sea el punto medular que fomente el desarrollo. Este enfoque tiene sus orígenes a partir de la Conferencia de las Naciones Unidas sobre Medio Ambiente y Desarrollo, en junio de 1992, este concepto se sustenta en un desarrollo local sustentable, promovido por habitantes y autoridades locales, quienes deben establecer estrategias de acción colectiva para la protección del ambiente, la prosperidad económica y el bienestar social dentro del ámbito local (Morales et al., 2006 y Ceballos, 2010).

Desde estas perspectivas, surge la necesidad de buscar alternativas e instrumentar estrategias de desarrollo local sustentable para los territorios rurales con problemas de vulnerabilidad y rezago social en donde los principales protagonistas del desarrollo sean los miembros de las sociedades locales, quienes deben impulsar el desarrollo social y económico de su comunidad sin poner en entredicho la conservación del ambiente, los recursos naturales y la identidad cultural de sus pobladores.

Para el municipio de Isidro Fabela que forma parte del Área Natural Protegida Parque Otomí-Mexica del Estado de México, el emergente deterioro ambiental de su territorio tiene una estrecha relación con el crecimiento habitacional de las metrópolis del centro de México. No obstante, la visión local de sus habitantes y autoridades sobre la conservación y aprovechamiento sustentable del territorio a partir del desarrollo de actividades inmersas en el marco del turismo rural, abre una posibilidad viable de implementar una estrategia de desarrollo local que considere entre sus objetivos la utilidad económica y al mismo tiempo la preservación y permanencia de los recursos naturales, sociales, económicos, políticos y culturales de su territorio. Siendo la acción colectiva y la equidad social de los habitantes y autoridades locales, el principio que detone el desarrollo local sustentable del territorio municipal. 


\section{Metodología}

La metodología de esta investigación se sustenta en las consideraciones conceptuales y metodológicas del turismo rural, el desarrollo local, el desarrollo sustentable, principios geográficos y sistemas complejos. Estos principios teórico-metodológico fueron vinculados con teorías y métodos de investigación participativa como: planeación partitiva, cartografía participativa, entrevistas estructuradas y análisis multicriterio; herramientas (cuestionarios y fotografías) e insumos geotecnológicos como: GPS, software, imágenes de satélite y mapas; y técnicas de trabajo de campo (observación directa, observación participante y recorridos de campo) que han demostrado ser eficientes en el desarrollo e instrumentación de estrategias de desarrollo local sustentable. En el siguiente diagrama (figura 1) se describe las fases metodológicas de la investigación.

\section{Figura 1: Diagrama metodológico general}

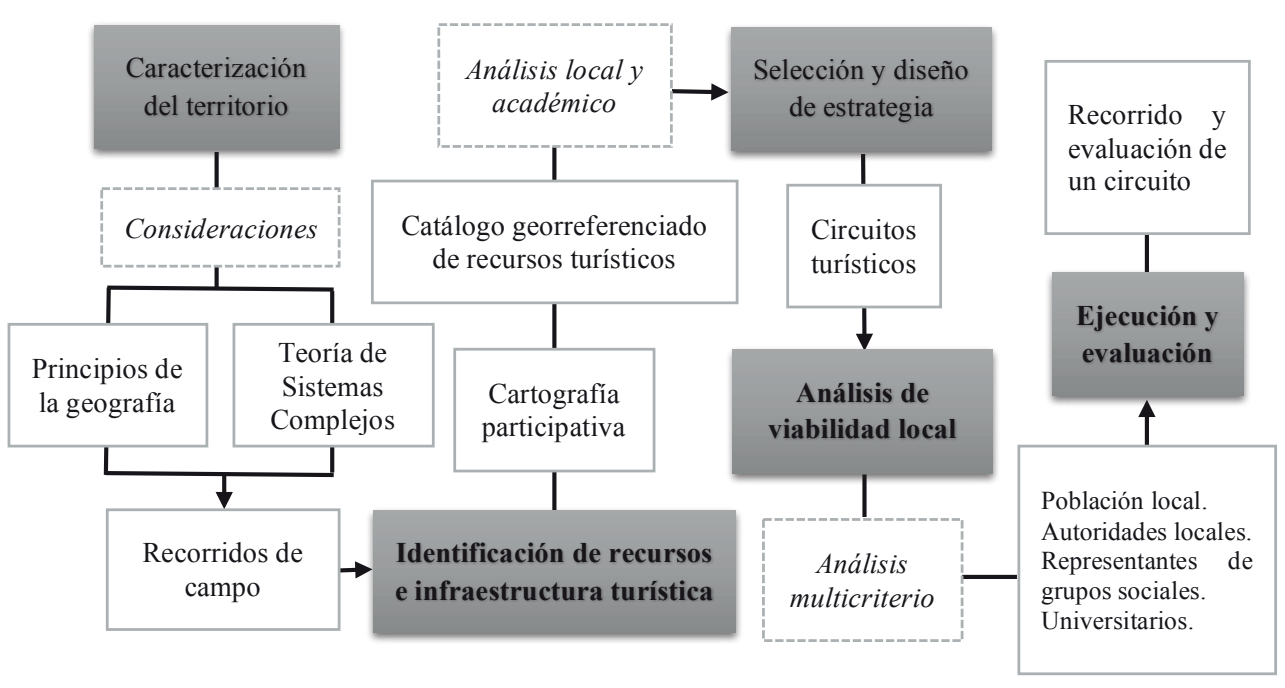

Fuente: Elaboración propia a partir de Geilfus, 2002.

\subsection{Interacción de habitantes y autoridades locales con integrantes de la universidad}

Esta fase se desarrolló bajo las consideraciones teóricas de la planeación participativa (Korstanje, 2008) enfoque que considera la participación activa de habitantes y autoridades locales en el desarrollo e instrumentación de estrategias de desarrollo local. Durante el acercamiento de habitantes y autoridades locales con integrantes de la universidad, se determinó que una estrategia viable mediante la cual es posible aprovechar y difundir los recursos del territorio desde una perspectiva local y sustentable, es a través de las actividades consideradas dentro del marco de estudio del turismo rural (etnoturismo, agroturismo, talleres locales y artesanales, senderismo y fotografía rural, entre otras), actividades que serán difundidas y practicadas mediante circuitos turísticos. Con esta estrategia, habitantes y representantes universitarios planearon realizar un aprovechamiento local, sustentable y ordenado de los recursos naturales y socioculturales disponibles en el territorio.

\subsection{Caracterización integral del territorial municipal de Isidro Fabela, Estado de México}

La caracterización de los componentes territoriales del municipio de Isidro Fabela, se sustentó en las consideraciones teóricas de los Sistemas Complejos (García, 2006) fundamentos que ayudaron a identificar y explicar las interrelaciones que existen entre los componentes geográficos del territorio (ubicación geográfica, fisiografía, geología, clima, hidrología, edafología y cuberturas del suelo) con las características socioculturales de las poblaciones que habitan dentro de los ambientes del territorio. El análisis y descripción de los componentes geográficos del territorio se realizó mediante la construcción 
de cartografía temática, el uso de imágenes de satélite SENTINEL 2 del año 2016 y con recorridos de campo por los diferentes ambientes que integran el espacio geográfico del municipio.

La caracterización de los componentes socioculturales (población, salud, educación, economía y aspectos culturales) se realizó mediante el análisis y descripción de información estadística de las 19 localidades que conforman la estructura social del municipio. Esta información fue obtenida de los servidores de información estadística del Instituto Nacional de Estadística y Geografía (INEGI), del Consejo Nacional de Población (CONAPO) y del Consejo Nacional de Evaluación de la Política de Desarrollo Social (CONEVAL), la cual fue comprobada directamente en las localidades que conforman al municipio.

\subsection{Identificación y ubicación geográfica de recursos e infraestructura con potencial turístico}

Esta fase de la investigación se desarrolló mediante la aplicación de la planeación participativa (Korstanje, 2009) y la cartografía participativa (FIDA, 2010). La aplicación de estos métodos permitió la difusión del proyecto a nivel local, así como la integración y participación de diversos sectores de la población. El método de la cartografía participativa se aplicó durante los recorridos de campo dirigidos por autoridades locales (regidora en turismo, coordinador de medio ambiente y la coordinadora de desarrollo social), representantes del grupo social de bienes comunales e integrantes de la Asociación de Artesanos y Comerciantes del Mercado Municipal y ocasionalmente por representantes de la población local. Durante los recorridos se ubicaron geográficamente los recursos, que la población local considera tienen potencial para el turismo.

Derivado de esta actividad se realizó la construcción de un catálogo georreferenciado de recursos con potencial turístico, los cuales fueron representados en tablas y mapas temáticos de acuerdo a la clasificación de la Organización Mundial del Turismo (OMT), la cual determina que los recursos turísticos de un territorio se deben clasificar de la siguiente manera: Tabla 1: Clasificación de recursos turísticos para el
municipio de Isidro Fabela, Estado de México.

\begin{tabular}{|l|l|l|}
\hline \multicolumn{1}{|c|}{ Culturales } & \multicolumn{1}{c|}{ Folclor } & \multicolumn{1}{c|}{ Naturales } \\
\hline Comerciales & Artesanías locales & Fauna, flora y hongos \\
\hline No comerciales & Festividades religiosas & Hábitats \\
\hline Históricos & Festividades culturales & Hidrológicos \\
\hline & & Miradores, peñas y barrancas \\
\hline
\end{tabular}

Fuente: Elaboración propia con base a la Organización Mundial del Turismo 2015.

A partir de esta clasificación, se diseñó la versión final del catálogo georreferenciado de los recursos turísticos del municipio, el cual consta de fichas de identificación con datos de la ubicación geográfica, información general de cada uno de los recursos identificados en campo, infraestructura turística existente y de los servicios complementarios disponibles en las comunidades del municipio.

\subsection{Diseño y trazado de circuitos turísticos}

Mediante la aplicación de los principios geográficos de localización (Ratzel, 1914), descripción (Vidal, 1917) y conexión-relación (Brunhes, 1920), se definieron una serie de criterios para el trazado de los circuitos turísticos, algunos de ellos fueron definidos a partir del acceso a materiales cartográficos (mapas temáticos e imágenes de satélite), del conocimiento local del territorio por parte de los habitantes, herramientas geotecnológicas, el conocimiento jurídico-administrativo de las autoridades del municipio y de las consideraciones técnicas de los integrantes de la universidad. 
Tabla 2: Criterios de trazado para los circuitos turísticos del municipio de Isidro Fabela, Estado de México.

\begin{tabular}{|l|l|l|l|}
\hline \multicolumn{1}{|c|}{ Figura } & \multicolumn{1}{|c|}{ Criterio de trazado } & \multicolumn{1}{c|}{ Equipo/material } & \multicolumn{1}{c|}{ Fuente } \\
\hline Universitarios & $\begin{array}{l}\text { Distribución espacial de recursos } \\
\text { turísticos (naturales y culturales) }\end{array}$ & GPS & Trabajo de campo \\
\hline Universitarios & $\begin{array}{l}\text { Distribución espacial de } \\
\text { infraestructura y servicios } \\
\text { turísticos }\end{array}$ & GPS & Trabajo de campo \\
\hline Universitarios & $\begin{array}{l}\text { Distribución espacial de servicios } \\
\text { complementarios }\end{array}$ & $\begin{array}{l}\text { Mapas de servicios } \\
\text { complementarios }\end{array}$ & $\begin{array}{l}\text { DENUE }{ }^{1} \text {-INEGI, trabajo } \\
\text { de campo }\end{array}$ \\
\hline Universitarios & Distancia a localidades & Mapa de localidades & INEGI \\
\hline Universitarios & Vías de comunicación & Mapa de vialidades & $\begin{array}{l}\text { Imagen Spot 5-trabajo } \\
\text { de campo y gabinete }\end{array}$ \\
\hline $\begin{array}{l}\text { Universitarios } \\
\text { y actores locales }\end{array}$ & Tenencia de la tierra & $\begin{array}{l}\text { Mapa de tenencia } \\
\text { de la tierra }\end{array}$ & RAN2 \\
\hline Actores locales & $\begin{array}{l}\text { Accesibilidad y disposición para } \\
\text { mostrar recursos }\end{array}$ & $\begin{array}{l}\text { Mapa de localización } \\
\text { de recursos turísticos }\end{array}$ & $\begin{array}{l}\text { Trabajo de campo } \\
\text { y gabinete }\end{array}$ \\
\hline $\begin{array}{l}\text { Universitarios } \\
\text { y actores locales }\end{array}$ & $\begin{array}{l}\text { Conflictos territoriales (zonas } \\
\text { de litigio) }\end{array}$ & $\begin{array}{l}\text { Mapa topográfico del } \\
\text { municipio }\end{array}$ & INEGI \\
\hline
\end{tabular}

Fuente: Elaboración propia.

Como se muestra en tabla anterior cada uno de los criterios de trazado cuenta con su material y la fuente de recopilación. Otros criterios que determinaron el trazado de los circuitos fueron tiempo de recorrido y la clasificación de los recursos (natural, cultural o mixto). Criterios que fueron determinados a partir de las preferencias del visitante, los cuales se obtuvieron a través de la aplicación de cuestionarios semiestructurados a un número representativo de visitantes (50 personas) los cuales fueron elegidos de manera aleatoria en el área de mayor afluencia turística del municipio (Presa Iturbide). Una vez definidos los criterios de trazado, éstos fueron automatizados en capas independientes en formato (shp) e introducidos a la plataforma de Arc-Gis 10.2, software que permitió la aplicación de metodologías de teledetección y cartografía automatizada (interpolación, reclasificación y análisis multicriterio) mediante las cuales se representaron de manera gráfica los circuitos turísticos.

\subsection{Viabilidad local de los circuitos turísticos}

La viabilidad local de los circuitos turísticos se determinó mediante el análisis multicriterio, método que sustenta sus bases científicas en la Teoría de la Acción Colectiva (Rodríguez, 2002.) la cual centra sus bases en la autoorganización social, que de acuerdo con Wolfe (1989) la podemos encontrar en "las familias, comunidades, redes de amistad, conexiones solidarias en los lugares de trabajo, voluntarismo, grupos espontáneos y movimientos". Para el caso de esta investigación este método permitió evaluar una serie de atributos que, según instancias gubernamentales, institutos de investigación e instancias académicas (universidades), involucrados con el desarrollo y evaluación de propuestas turísticas ha sido utilizado para evaluar la viabilidad de rutas, senderos y circuitos turísticos en territorios rurales (tabla 3). 


\section{Tabla 3: Atributos seleccionados para evaluar la viabilidad de los circuitos turísticos del municipio de Isidro Fabela, Estado de México.}

\begin{tabular}{|l|l|}
\hline \multicolumn{1}{|c|}{ Atributo } & \multicolumn{1}{c|}{ Descripción } \\
\hline Accesibilidad & $\begin{array}{l}\text { Mide el grado de acceso que tienen los visitantes externos sobre los recursos y } \\
\text { servicios turísticos del territorio }\end{array}$ \\
\hline $\begin{array}{l}\text { Conectividad con otras } \\
\text { zonas turísticas }\end{array}$ & $\begin{array}{l}\text { Atributo utilizado para determinar la viabilidad de conexión existente entre el } \\
\text { territorio de estudio y otras áreas turísticas de la región. }\end{array}$ \\
\hline $\begin{array}{l}\text { Conservación de } \\
\text { recursos turísticos }\end{array}$ & $\begin{array}{l}\text { Se utilizó para medir el nivel de conservación de los recursos naturales y } \\
\text { culturales considerados en cada circuito turístico. }\end{array}$ \\
\hline $\begin{array}{l}\text { Disposición para } \\
\text { mostrar recursos }\end{array}$ & $\begin{array}{l}\text { Decreta el grado de disponibilidad que tienen los habitantes del municipio para } \\
\text { mostrar los recursos naturales y culturales de su territorio a personas externas. }\end{array}$ \\
\hline $\begin{array}{l}\text { Distancia a zonas } \\
\text { urbanas }\end{array}$ & $\begin{array}{l}\text { Considera la distancia en tiempo que existe entre los circuitos turísticos y la } \\
\text { zona urbana del municipio (cabecera municipal) }\end{array}$ \\
\hline $\begin{array}{l}\text { Infraestructura y } \\
\text { servicios }\end{array}$ & $\begin{array}{l}\text { Fundamenta la calidad de servicios e infraestructura turística involucrada en el } \\
\text { trayecto de los circuitos turísticos. }\end{array}$ \\
\hline $\begin{array}{l}\text { Relación territorial con } \\
\text { otros municipios }\end{array}$ & $\begin{array}{l}\text { Mide la relación existente entre los grupos sociales (comunal y ejidal) del } \\
\text { municipio y los grupos sociales de los municipios colindantes. }\end{array}$ \\
\hline Seguridad & $\begin{array}{l}\text { Determina la sensación de seguridad que tienen los habitantes respecto a su } \\
\text { territorio. }\end{array}$ \\
\hline Señalética & $\begin{array}{l}\text { Evalúa la calidad y cantidad de letreros visuales disponibles en el territorio } \\
\text { para la ubicación de servicios turísticos. }\end{array}$ \\
\hline Vías de acceso & $\begin{array}{l}\text { Establece el estado de conservación de las vías de comunicación involucradas en } \\
\text { el desarrollo y recorrido de los circuitos }\end{array}$ \\
\hline
\end{tabular}

Fuente: Elaboración propia.

La evaluación de los atributos presentados en la tabla anterior se sustentó en el conocimiento territorial de los pobladores locales, conocimientos administrativos y jurídicos de las autoridades municipales y conocimientos científicos de los integrantes de la universidad, quienes fungieron como figuras evaluadoras de los atributos definidos para cada uno de los circuitos turísticos, mismos que se presentan en la siguiente tabla.

Tabla 4: Clasificación de atributos de acuerdo a la figura evaluadora.

\begin{tabular}{|c|c|c|c|c|}
\hline \multirow[b]{2}{*}{ No. } & \multirow[b]{2}{*}{ Atributo } & \multicolumn{3}{|c|}{ Figura Evaluadora } \\
\hline & & $\begin{array}{c}\text { Población y } \\
\text { representantes } \\
\text { sociales }\end{array}$ & $\begin{array}{c}\text { Autoridades } \\
\text { locales }\end{array}$ & Universitarios \\
\hline 1 & Accesibilidad & $\mathrm{x}$ & & \\
\hline 2 & Conectividad con otras zonas turísticas & & & $\mathrm{x}$ \\
\hline 3 & Conservación de recursos turísticos & & & $\mathrm{x}$ \\
\hline 4 & Disposición para mostrar recursos & $\mathrm{x}$ & & \\
\hline 5 & Distancia a zonas urbanas & & & $\mathrm{x}$ \\
\hline 6 & Infraestructura y servicios & & $\mathrm{x}$ & \\
\hline 7 & Relación territorial con otros municipios & $\mathrm{x}$ & & \\
\hline 8 & Seguridad & $\mathrm{x}$ & & \\
\hline 9 & Señalética & & $\mathrm{x}$ & \\
\hline 10 & Vías de acceso & & $\mathrm{x}$ & \\
\hline
\end{tabular}

Fuente: Elaboración propia. 
Cada atributo fue calificado en una escala de 1-10, considerando el rango mayor con mejor viabilidad. La evaluación de los atributos se realizó mediante una matriz tabular, la cual fue entregada a los participantes durante el desarrollo de los talleres participativos efectuados en las instalaciones del Mercado Municipal, el Ayuntamiento y la Biblioteca Municipal de Isidro Fabela. De acuerdo con su criterio y experiencia personal cada uno de los asistentes evaluaron los atributos correspondientes. Antes de realizar la evaluación de los atributos de cada uno de los circuitos turísticos, estos fueron presentados mediante una serie de mapas, explicando a detalle el tipo de recursos que lo conforman, el territorio municipal que comprende cada uno de ellos, el tiempo de recorrido, las actividades viables en cada punto y los servicios e infraestructura turísticas disponibles. Posterior a esta actividad se realizó la evaluación de viabilidad local de cada circuito.

Al finalizar los talleres participativos, se realizó la integración de las evaluaciones correspondientes las cuales fueron sumadas para posteriormente obtener la media y con ello definir la ponderación final de cada circuito. Consecutivamente se determinó una serie de rangos: a) 5-6 poco viable; b) 7-8 medianamente viable y c) 9-10 viable, mediante los cuales se definió la viabilidad local de cada uno de los circuitos turísticos.

\subsection{Evaluación participativa de un circuito turístico}

Esta actividad se realizó mediante la selección y recorrido por el circuito turístico que resultó ser viable durante el desarrollo de la evaluación local. Con la conformación de un grupo de 15 estudiantes

universitarios, tres representantes locales, dos actores sociales y dos profesores universitarios

se realizó el recorrido por el circuito seleccionado. Los participantes fueron trasladados al punto de inicio del recorrido donde les fue entregado un documento con la representación cartográfica de los componentes y peculiaridades del circuito. El recorrido inició a la 8:00 horas y terminó aproximadamente a las 17:00 horas. Durante el trayecto se explicó a los participantes las características específicas y la importancia de cada uno de los componentes y ambientes locales.

Previamente al recorrido se informó a los participantes la disposición de una hora para el consumo de alimentos y descanso en uno de los establecimientos locales. Después de concluido el recorrido, a cada participante le fue proporcionado un cuestionario con diez preguntas para evaluar algunas características del circuito: tiempo del recorrido, conservación de los recursos turísticos, potencial turístico y disposición a pagar a un guía por el recorrido e interpretación de los componentes observados. Posteriormente a esta actividad se hizo la recopilación de información de los cuestionarios a través de una matriz tabular que permitió la construcción de gráficas, con las cuales se determinó la viabilidad del circuito turístico. Con esta actividad se tuvo una perspectiva de análisis de adentro hacia afuera y de afuera hacia adentro y se determina que la evaluación del circuito turístico se realizó desde los principios del enfoque integral del desarrollo local sustentable y del turismo rural.

\section{Resultados}

\subsection{Caracterización integral del territorial}

El municipio de Isidro Fabela se encuentra ubicado en la zona centro del Estado de México, en la porción norte del Área Natural Protegida, Parque Ecológico Turístico y Recreativo Zempoala La Bufa, denominado Parque Otomí Mexica del Estado de México, en una zona conocida localmente como Monte-Alto (Figura 1). Fisiográficamente el territorio municipal está formado por un relieve accidentado que presenta profundas cañadas en dirección este-oeste, acompañadas de una serie de elevaciones (volcanes), el promedio altitudinal del territorio oscila entre 2,325 y 3,765 msnm (INEGI-CEM, 2015).

La latitud y las características topográficas del territorio son elementos geográficos que determinan las condiciones climáticas presentes en la región. El clima es semifrío-subhúmedo con lluvias en el verano $\mathrm{C}(\mathrm{E})(\mathrm{w})(\mathrm{w})$, característico de zonas de montaña en México, la temperatura oscila entre los $25^{\circ} \mathrm{C}$ en verano y los $-5^{\circ} \mathrm{C}$ en la fase más aguda del invierno (mes de enero). Dentro del espacio geográfico de estudio, existen una serie de manantiales de aguas cristalinas principalmente en las zonas de montaña, cuerpos de agua que dan origen a ríos y escurrimientos vitales para el desarrollo de las coberturas arbóreas, arbustivas y herbáceas, entre las que destaca los bosques de pino (Pinus hartwegii) que ocupan las partes altas del territorio, en las zonas de mediana altitud existen cañadas en donde se desarrollan los bosques de oyamel (Abies religiosa) (García, 1990 e INEGI, 2016). 
Figura 1: Ubicación geográfica del municipio de Isidro Fabela, Estado de México.

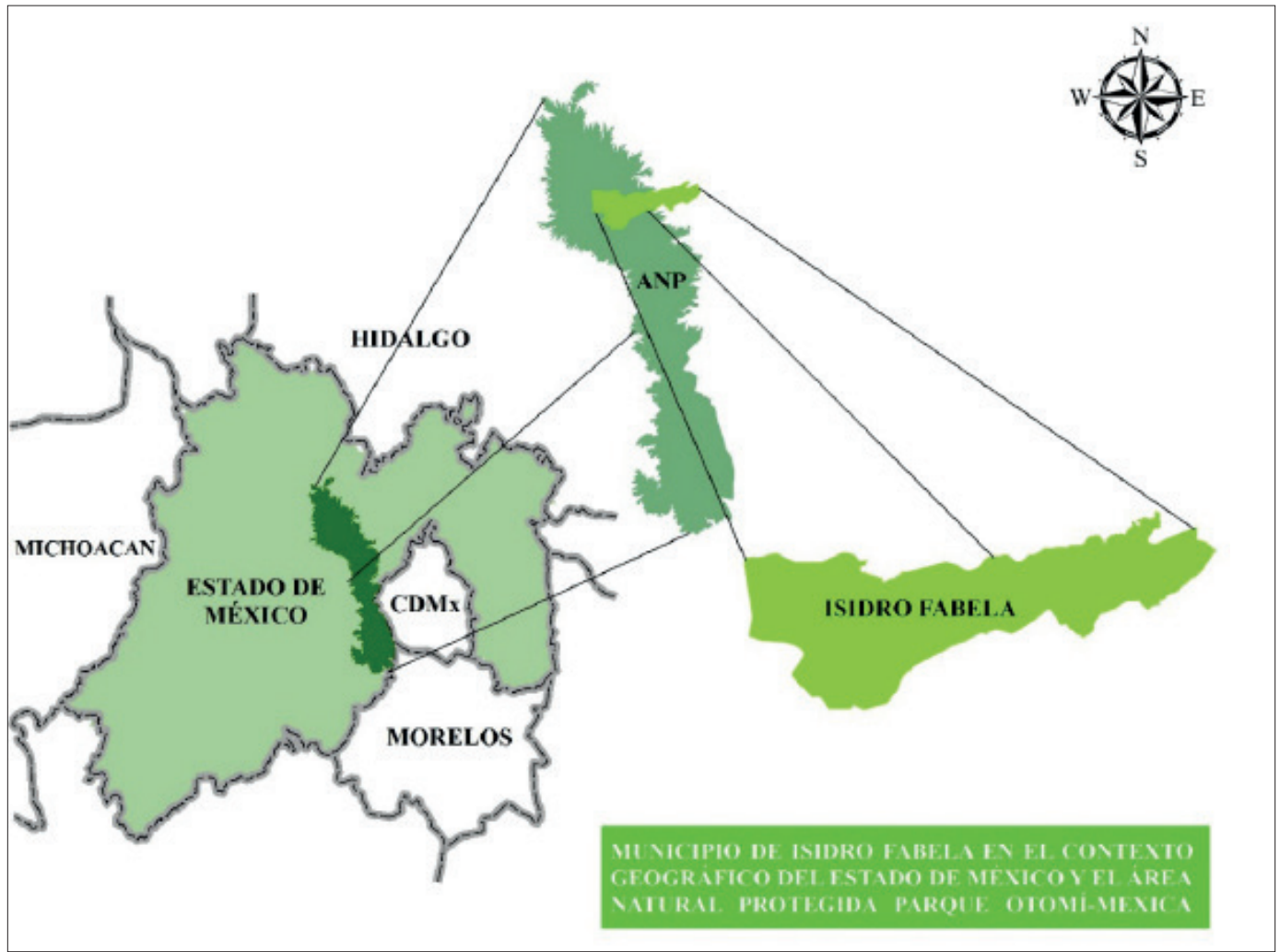

Fuente: Elaboración propia.

Los bosques encino (Quercus ssp.) se desarrollan en las partes bajas del territorio municipal, donde las pendientes son menores a $35^{\circ}$, característica topográfica que ha permitido que esta y otras especies arbóreas sean impactadas por el desarrollo de actividades agrícolas, ganaderas y por el constante crecimiento de las zonas habitacionales. Actualmente en este espacio geográfico el bosque de encinos ha sido uno de los más afectadas por los procesos de cambios que presentan las coberturas del suelo, las pequeñas áreas del territorio municipal que aún conservan su cubierta del suelo original sirven de manera conjuntan con especies introducidas de cedro blanco, capulín y otros árboles frutales como límite natural de parcelas, rancherías y localidades (INEGI, 2016).

Desde el punto de vista social y político, el territorio de Isidro Fabela está constituido administrativamente por 19 localidades, una de ellas es la cabecera municipal (Tlazala de Fabela). Ninguna de las localidades del municipio tiene más de 2,500 habitantes, característica administrativa que clasifica al territorio como rural. Para el año 2015 el municipio tenía una población de 11,726 habitantes de los cuales 5,804 son hombres y el resto mujeres, al asociar la extensión territorial del municipio y el número de habitantes se estima que la densidad de población es de 175 habitantes $/ \mathrm{km}^{2}$. La población del municipio es relativamente joven ya que el 55\% se concentra en los grupos quinquenales menores a 34 años, por su parte la población económicamente activa (PEA) constituye el $37.03 \%$ de la población total y las principales actividades económicas que desarrollan se encuentran clasificadas dentro sector terciario (comercio al por menor y transporte) de las cuales las familias del municipio obtienen su principal ingreso económico (INEGI, 2015 y SEDESOL, 2013).

La estructura económica no ha sido suficiente para dar sustento a su población y amortiguar los altos niveles de marginación que presentan las localidades del municipio, obligando con ello a la población y autoridades locales a buscar nuevas alternativas de desarrollo que fomenten el crecimiento económico del municipio y el desarrollo humano. La caracterización integral del territorio municipal fue útil para determinar el estado actual de sus componentes y su relación con ambientes adyacentes en el contexto del área natural protegida. La caracterización integral es de vital importancia para la planeación de 
estrategias de desarrollo local sustentable, ya que a partir de los datos obtenidos se puede tener una percepción detallada sobre los componentes territoriales (biofísicos y socioculturales) y su estado actual, los cuales son importantes para la planeación y toma de decisiones de los territorios rurales en México.

\subsection{Clasificación y ubicación geoespacial de recursos e infraestructura turística}

Resultado de los recorridos de campo, la participación social y la aplicación de cuestionarios, se hizo la caracterización y ubicación geoespacial de 115 recursos turísticos (Mapa 1), los cuales fueron agrupados en tres categorías (Tabla 5) y caracterizados mediante fichas de identificación (Figura 2). La infraestructura existente en el municipio de Isidro Fabela y destinada a proporcionar servicios a los visitantes está compuesta de nueve granjas productoras de trucha (trucheros), cuatro ofrecen servicio de hospedaje en cabañas rústicas y una ofrece el servicio de campamento. En estos espacios se oferta a los visitantes el servicio de alimentos y bebidas, con gran variedad de guisados a base de productos locales como quelites, hongos, maíz y carne de animales criados en las mismas granjas, este tipo de infraestructura se encuentra ubicada principalmente en la zona de montaña.

Tabla 5: Clasificación de recursos turísticos del municipio de Isidro Fabela, Estado de México.

\begin{tabular}{|l|c|c|c|c|c|}
\hline \multicolumn{6}{|c|}{ Recursos turísticos } \\
\hline \multicolumn{1}{|c|}{ Naturales } & Núm. & Culturales & Núm. & Folclóricos & Núm. \\
\hline Hábitat & 5 & Comerciales & 16 & Artesanías & 12 \\
Flora & 10 & No comerciales & 5 & Festividades religiosas & 3 \\
Fauna & 10 & Históricos & 8 & Festividades culturales & 3 \\
Hongos & 10 & & & & \\
Hidrológicos & 6 & & & & \\
Barrancas & 1 & & & & \\
Peñas & 2 & & & & \\
Miradores & 24 & & $\mathbf{2 9}$ & & \\
\multicolumn{1}{|c|}{ Total } & $\mathbf{6 8}$ & & & & \\
\hline
\end{tabular}

Fuente: Elaboración propia.

Figura 2: Ficha de identificación de recursos.

MIRADOR 1. CERRO DE
LAGUNA SECA
Coordenadas: $\mathrm{x}: 447312$ y: 2162412 .
Altitud: $3633 \mathrm{msnm}$.
Municipio: Isidro Fabela.
Localidad: Las Palomas.
Tipo de tenencia: Comunal.
Administra: Sociedad de bienes
comunales.
Categoría: Mirador Natural.
Descripción: Mirador ubicado en la
ladera Sur del cerro de Laguna Seca.
Desde este punto se puede apreciar el
paisaje sur del territorio.
Vía de acceso: Vereda sinuosa.
Acceso al recurso: Pie.
Tipo de acceso: Libre.
Época propicia de visita: Todo el
año. Infraestructura: Ninguna.
Actividades a desarrollar:
Paisajismo, fotografia y video.
Servicios actuales: Ninguno. Alimentación: Ninguno. Lugares de esparcimiento: Bosques de pino y
peñas. Otros servicios: Ninguno.

Fuente: Elaboración propia. 
En la cabecera municipal de Isidro Fabela se concentra el mayor número de servicios, entre los cuales se puede destacar dos hoteles tres estrellas, un hotel boutique (El refugio del Águila), un hotel campestre y un hotel-balneario. Existen 11 establecimientos que ofrecen servicios de alimentos y bebidas, y un número considerable de servicios complementarios como: servicios bancarios, cajeros automáticos, dos módulos de seguridad pública, un Centro Especializado de Atención Primaria a la Salud (CEAPS), un centro de salud rural, cuatro unidades deportivas con gimnasio al aire libre, un parque recreativo, dos viveros forestales, un centro comercial pequeño, cinco talleres mecánicos, comercios de comida rápida, papelerías, centros de cómputo, farmacias y misceláneas.

\section{Mapa 1: Representación geoespacial de los recursos turísticos del municipio de Isidro Fabela, Estado de México.}

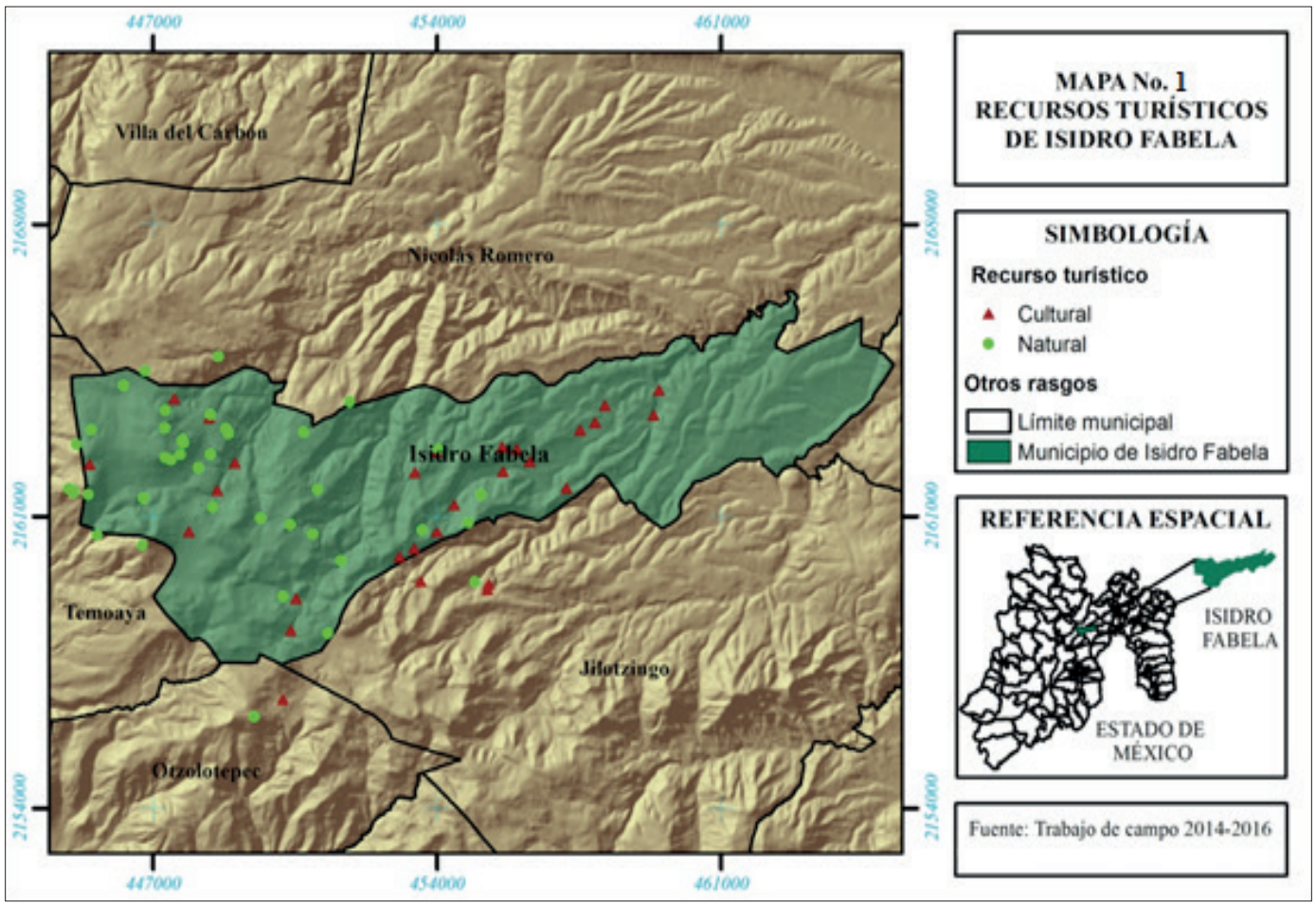

Fuente: Elaboración propia.

\subsection{Diseño y trazado de circuitos turísticos}

El diseño y construcción de los circuitos de turísticos, está pensado como una estrategia de desarrollo local sustentable, ya que han sido los mismos habitantes quienes han sugerido que los circuitos pueden ser una estrategia viable para implementar y difundir de manera ordenada y sustentable actividades de turismo rural dentro de su territorio municipal. Así mismo los representantes de la universidad esperan que los circuitos turísticos sean el eje rector que permita la inclusión y difusión de infraestructura turística y de servicios complementarios, además de ser el detonante principal de nuevos canales de comercialización para productos y artesanías locales, la generación de empleos vinculados con la prestación de servicios turísticos y el medio de adecuado para la preservación y valoración de recursos inmersos en territorios rurales de México. El resultado más representativo que se obtuvo en esta fase de la investigación son ocho circuitos turísticos representados cartográficamente, algunas de sus características generales de cada circuito se presentan en el siguiente mapa y en la tabla 6.

Derivado de la instrumentación de los circuitos turísticos, se espera tener un control adecuado en el desarrollo de actividades turísticas dentro del territorio municipal y con ello evitar la desarticulación 
de las personas que realizan este tipo de actividades. Además, se espera que los circuitos sean un instrumento valioso para evitar la equivocada difusión turística del territorio, ya que en la actualidad la difusión errónea del turismo dentro del municipio ha provocado que más del $97 \%$ de los visitantes se concentren solamente en un punto del territorio (Presa Iturbide). Problemática que actualmente está generando impactos negativos sobre el ambiente los más comunes son: erosión del suelo generada por la apertura de nuevos caminos de forma irregular y desordenada y procesos de fragmentación ecosistémica, fenómeno que incide de manera directa en la disminución de comunidades vegetales, provocando una reducción importante del hábitat para la fauna local.

\section{Mapa 2: Representación geoespacial de los circuitos de turismo rural del municipio de Isidro Fabela, Estado de México.}

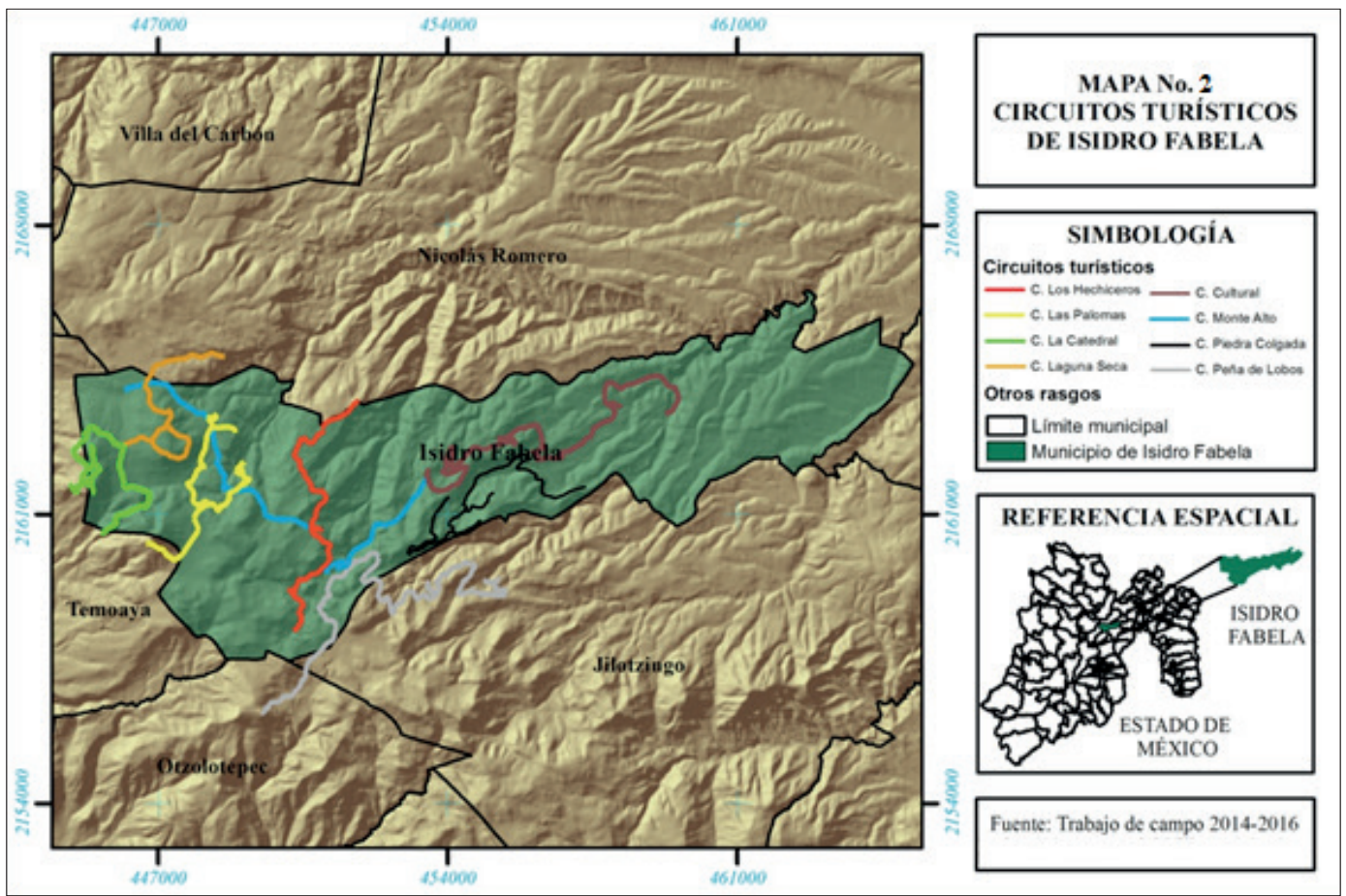

Fuente: Elaboración propia. 
Tabla 6: Características generales de los circuiticos turísticos del municipio de Isidro Fabela, Estado de México.

\begin{tabular}{|l|c|c|c|c|c|c|}
\hline \multicolumn{1}{|c|}{$\begin{array}{c}\text { Circuito } \\
\text { turístico }\end{array}$} & $\begin{array}{c}\text { Distancia } \\
\mathbf{( K m )}\end{array}$ & $\begin{array}{c}\text { Duración } \\
\text { aproximada }\end{array}$ & $\begin{array}{c}\text { Altitud } \\
\text { promedio } \\
\mathbf{( m s n m )}\end{array}$ & Relieve & $\begin{array}{c}\text { No. de } \\
\text { recursos }\end{array}$ & $\begin{array}{c}\text { Distancia } \\
\text { a cabecera } \\
\text { municipal }\end{array}$ \\
\hline Monte-Alto & 15.5 & 8 horas & 3300 & $\begin{array}{c}\text { Montañoso } \\
\text { semiplano }\end{array}$ & 10 & 35 minutos \\
\hline Laguna Seca & 7.4 & 5 horas & 3595 & $\begin{array}{c}\text { Montañoso } \\
\text { accidentado }\end{array}$ & 10 & 30 minutos \\
\hline La Catedral & 8.7 & 6 horas & 3610 & $\begin{array}{c}\text { Montañoso } \\
\text { accidentado }\end{array}$ & 10 & 40 minutos \\
\hline Las Palomas & 10.5 & 7 horas & 3418 & $\begin{array}{c}\text { Montañoso } \\
\text { semiplano }\end{array}$ & 10 & 25 minutos \\
\hline Peña de Lobos & 15.2 & 8 horas & 3216 & $\begin{array}{c}\text { Montañoso } \\
\text { semiplano }\end{array}$ & 9 & 45 minutos \\
\hline Piedra Colgada & 11.1 & 7 horas & 3050 & $\begin{array}{c}\text { Montañoso } \\
\text { accidentado }\end{array}$ & 9 & 15 minutos \\
\hline Los Hechiceros & 8.8 & 6 horas & 3290 & $\begin{array}{c}\text { Montañoso } \\
\text { semiplano }\end{array}$ & 10 & 25 minutos \\
\hline Cultural & 8.7 & 8 horas & 3600 & $\begin{array}{c}\text { Montañoso } \\
\text { accidentado }\end{array}$ & 11 & 10 minutos \\
\hline
\end{tabular}

Fuente: Elaboración propia.

\subsection{Evaluación multicriterio para determinar la viabilidad local de los circuitos turísticos}

Por medio de talleres participativos, se presentaron a pobladores, autoridades locales y representantes sociales (ejidatarios y comuneros) la distribución espacial de los ocho circuitos turísticos previamente diseñados y con ello obtener su respectiva opinión. Durante el desarrollo de los tres talleres participativos se tuvo una participación total de 55 habitantes, cinco autoridades locales, tres representantes sociales, seis integrantes del grupo de artesanos y comerciantes, una empleada regional promotora del turismo en el Estado de México y ocho integrantes de la universidad (profesores y estudiantes), quienes de acuerdo a sus conocimientos y experiencias se les asignaron una serie de atributos que debían evaluar (fotografía 1).

A cada atributo se le asignó una ponderación del 1-10, considerando de mayor viabilidad el valor 10. Los resultados obtenidos producto de la realización de los talleres participativos, la participación social y administrativa del ayuntamiento, se muestran de forma numérica en la matriz ponderada (tabla 7). Con la aplicación de métodos estadísticos se obtuvo la suma lineal ponderada que determinó la ponderación final de cada circuito turístico y con ellos su viabilidad local (5-6 poco viable; 7-8 medianamente viable y de 9-10 viable). En la tabla ocho se presentan los rangos de vialidad para cada uno de los circuitos. 
Fotografía 1: Taller participativo. Evaluación de viabilidad local de los circuitos turísticos del municipio de Isidro Fabela, Estado de México.

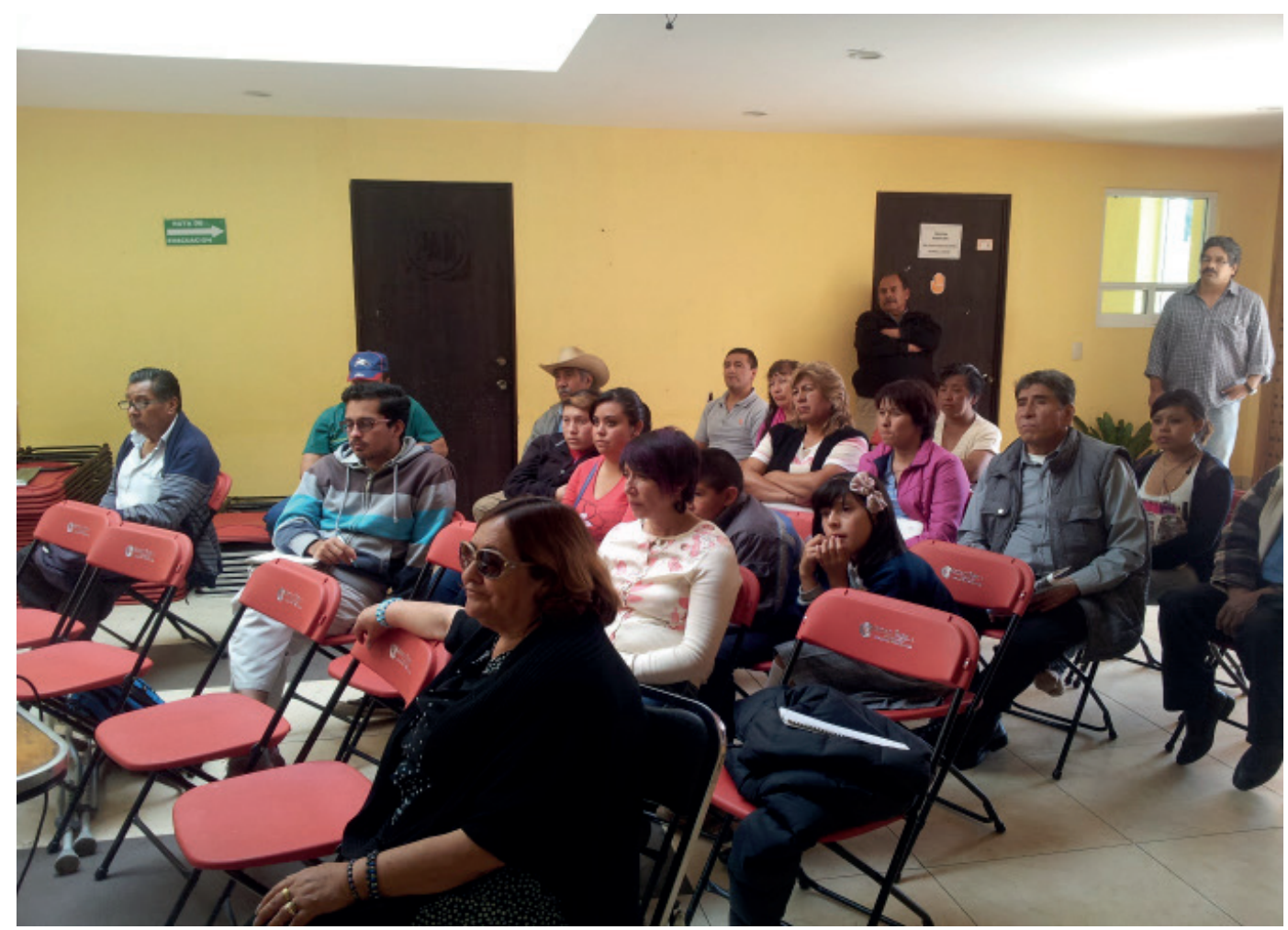

Fuente: Trabajo de campo 2016.

Tabla 7: Matriz de viabilidad ponderada de los circuitos turísticos del municipio de Isidro Fabela.

\begin{tabular}{|l|c|c|c|c|c|c|c|c|c|c|c|}
\hline \multirow{2}{*}{$\begin{array}{l}\text { Circuito turístico/ } \\
\text { No. de Atributo }\end{array}$} & \multicolumn{9}{|c|}{ Población y autoridades locales } & \multicolumn{3}{c|}{ Personal técnico } & Suma lineal \\
\cline { 2 - 13 } & $\mathbf{1}$ & $\mathbf{2}$ & $\mathbf{3}$ & $\mathbf{4}$ & $\mathbf{5}$ & $\mathbf{6}$ & $\mathbf{7}$ & $\mathbf{8}$ & $\mathbf{9}$ & $\mathbf{1 0}$ & $\begin{array}{c}\text { ponderada } \\
\text { Monte Alto }\end{array}$ \\
\hline & 10 & 8.6 & 9.3 & 10 & 8 & 5.6 & 8.2 & 8 & 10 & 8 & $\mathbf{9 5 . 7}$ \\
\hline Laguna Seca & 10 & 8.4 & 9.2 & 10 & 7.3 & 5.7 & $\mathrm{x}^{3}$ & 8 & 10 & 10 & $\mathbf{8 7 . 2}$ \\
\hline Cerro la Catedral & 5.7 & 6.6 & 7.6 & 9.2 & 8.2 & 5.6 & $\mathrm{x}$ & 8 & 10 & 10 & $\mathbf{7 7 . 5}$ \\
\hline Las Palomas & 10 & 8.8 & 9.2 & 10 & 7.6 & 5.6 & 7.9 & 8 & 10 & 6 & $\mathbf{9 1 . 7}$ \\
\hline Peña de Lobos & 9.7 & 8.8 & 9.3 & 10 & 8.6 & 5.8 & 7.5 & 8 & 10 & 8 & $\mathbf{9 5 . 7}$ \\
\hline Piedra Colgada & 10 & 8.4 & 9.6 & 10 & 8 & 5.6 & 8.7 & 10 & 10 & 8 & $\mathbf{9 6 . 9}$ \\
\hline Los Hechiceros & 9.5 & 8.2 & 8.6 & 10 & 7.3 & 5.6 & 8.8 & 10 & 10 & 8 & $\mathbf{9 4 . 6}$ \\
\hline Cultural & 10 & 8.2 & 9.7 & 10 & 8.9 & 7.6 & 9.4 & 10 & 8 & 8 & $\mathbf{9 7 . 8}$ \\
\hline
\end{tabular}

Acotaciones: 1= relación territorial con otros municipios, $2=$ accesibilidad, $3=$ seguridad, $4=$ disposición para mostrar recursos, $5=$ vías de acceso, $6=$ señalética, $7=$ infraestructura y servicios, $8=$ distancia a zonas urbanas. $9=$ conectividad con otras zonas turísticas y $10=$ conservación de recursos turísticos.

Fuente: Elaboración propia. 
De los ocho circuitos turísticos propuestos, cinco resultaron viables desde las tres perspectivas de análisis (población local, autoridades locales y universitarios) partícipes en los talleres participativos. Con estos resultados se determina que los actores locales interesados en implementar los circuitos como una actividad económica adicional pueden comenzar a desarrollar actividades complementarias (organización social y difusión) para su futura apertura en la oferta turística local y regional. Desde la propuesta y diseño de los circuitos se determinó mediante una consulta local que serían los propios pobladores del municipio los encargados de administrar, desarrollar y difundir de manera ordenada y sustentables toda acción o actividad vinculada con la instrumentación de los circuitos y con ello cumplir con los objetivos del desarrollo local sustentable, esto a partir de las actividades vinculadas con el turismo rural.

Tabla 8: Viabilidad de circuitos de turismo rural.

\begin{tabular}{|l|c|c|l|}
\hline \multicolumn{1}{|c|}{ Circuito turístico } & $\begin{array}{c}\text { Suma lineal } \\
\text { ponderada }\end{array}$ & Ponderación final & \multicolumn{1}{|c|}{ Nivel de viabilidad } \\
\hline Monte Alto & 95.7 & 9 & Viable \\
\hline Laguna Seca & 87.2 & 8 & Medianamente viable \\
\hline La Catedral & 77.5 & 7 & Medianamente viable \\
\hline Las Palomas & 91.7 & 8 & Medianamente viable \\
\hline Peña de Lobos & 95.7 & 9 & Viable \\
\hline Piedra Colgada & 96.9 & 9 & Viable \\
\hline Los Hechiceros & 94.6 & 9 & Viable \\
\hline Cultural & 97.8 & 9 & Viable \\
\hline
\end{tabular}

Fuente: Elaboración propia.

Para el caso de los tres circuitos turísticos que resultaron ser medianamente viables desde el análisis multicriterio, se propone que antes de su instrumentación se analicé de manera detallada aquellos atributos que obtuvieron los niveles de ponderación más bajos e implementar estrategias de solución que mejoren su nivel de viabilidad, realizadas estas recomendaciones los habitantes locales pueden tener mejores resultados al momento de su implementación. De acuerdo con el análisis local y académico realizado durante esta investigación, se consideró apropiado obtener una perspectiva externa para determinar la viabilidad de un circuito, esto en función de las preferencias y necesidades de los participantes. Para obtener esta perspectiva se realizó un recorrido por el circuito turístico Peña de Lobos, en el cual se tuvo la participación de 20 personas (97\% residentes de otros municipios y la Ciudad de México).

\subsection{El Circuito Turístico Peña de Lobos: Un caso de implementación y evaluación}

El circuito turístico Peña de Lobos fue elegido para realizar un recorrido, ya que este resultó viable desde la evaluación local y académica. El objetivo de esta actividad fue determinar la viabilidad del circuito desde una perspectiva externa (visitantes), esta actividad proporcionó un soporte adicional a los datos obtenidos durante del desarrollo de los talleres participativos y con ello se dio sustento al trabajo metodológico de esta investigación desde una perspectiva local, académica y externa.

Los resultados obtenidos muestran que 55\% de los participantes consideran al recorrido del Circuito Turístico Peña de Lobos, bueno, por su parte, 40\% lo definen como muy bueno y sólo el 5\% lo consideró como regular. Las perspectivas que motivaron a los visitantes a calificar el recorrido como bueno y muy bueno $(95 \%)$ se sustentan principalmente en la belleza y conservación natural de los componentes del paisaje del circuito seleccionado. La mayoría consideró a los componentes del circuito como un paisaje natural hermoso, limpio y totalmente diferente a las zonas turísticas presentes en el territorio del Parque Otomí-Mexica del Estado de Mexica. Por su parte el 5\% que calificó el recorrido como regular, manifestaron que su decisión se debe principalmente al tiempo de recorrido, ya que este porcentaje mínimo de participantes considera que ocho horas caminando es excesivo. Sin embargo, algunos de 
ellos comentaron que estarían dispuestos a recorrer los siete circuitos turísticos restantes, siempre y cuando las condiciones ambientales fueran similares y el relieve menos accidentado.

Con relación a la percepción que determina la conservación de los recursos turísticos considerados dentro del trayecto, el $75 \%$ de los participantes consideró que su estado de conservación es muy bueno y el $25 \%$ opina que la conservación de los recursos es buena, la principal característica del territorio que motivó a los participantes a calificar el estado de conservación de los recursos como bueno y muy bueno, se debe principalmente a la esencia campestre que actualmente tiene el territorio. Este atributo fue valorado positivamente por los participantes, ya que $90 \%$ de ellos habita en localidades urbanas en donde según ellos las condiciones ambientales son deplorables.

Es importante mencionar que al inicio del recorrido a cada uno de los participantes se le entregó un documento impreso que contenía las características generales del recorrido, el tipo de actividad o actividades que se pueden realizar en cada punto y recomendaciones para hacer del recorrido una actividad turística segura, amigable y respetuosa con el ambiente y las localidades establecidas en el territorio. Como información adicional se les proporcionó un mapa impreso con la representación gráfica del trayecto del circuito y mediante una serie de fotos se dan a conocer los recursos naturales y culturales que serán visitados durante el recorrido (mapa 3).

Con respecto, a la percepción sobre el potencial turístico que puede tener el Circuito Turístico Peña de Lobos, 98\% considera que la diversidad y conservación de los recursos naturales y los paisajes que se consideran dentro del recorrido, son atributos significativos que detonarán positivamente el potencial turístico de los circuitos y del territorio, por su parte, $2 \%$ expone que el circuito recorrido y los circuitos con características naturales similares pueden tener problemas al momento de impulsarlos como una actividad turística, ya que los recorridos no están diseñados para realizarse en familia o con personas discapacitadas. Opinan que los circuitos están diseñados para un sector turístico con experiencia preferencias por caminar en territorios campestres, situación que podría minimizar el potencial turístico de los circuitos.

\section{Mapa 3: Representación cartográfica del Circuito Turístico Peña de Lobos.}

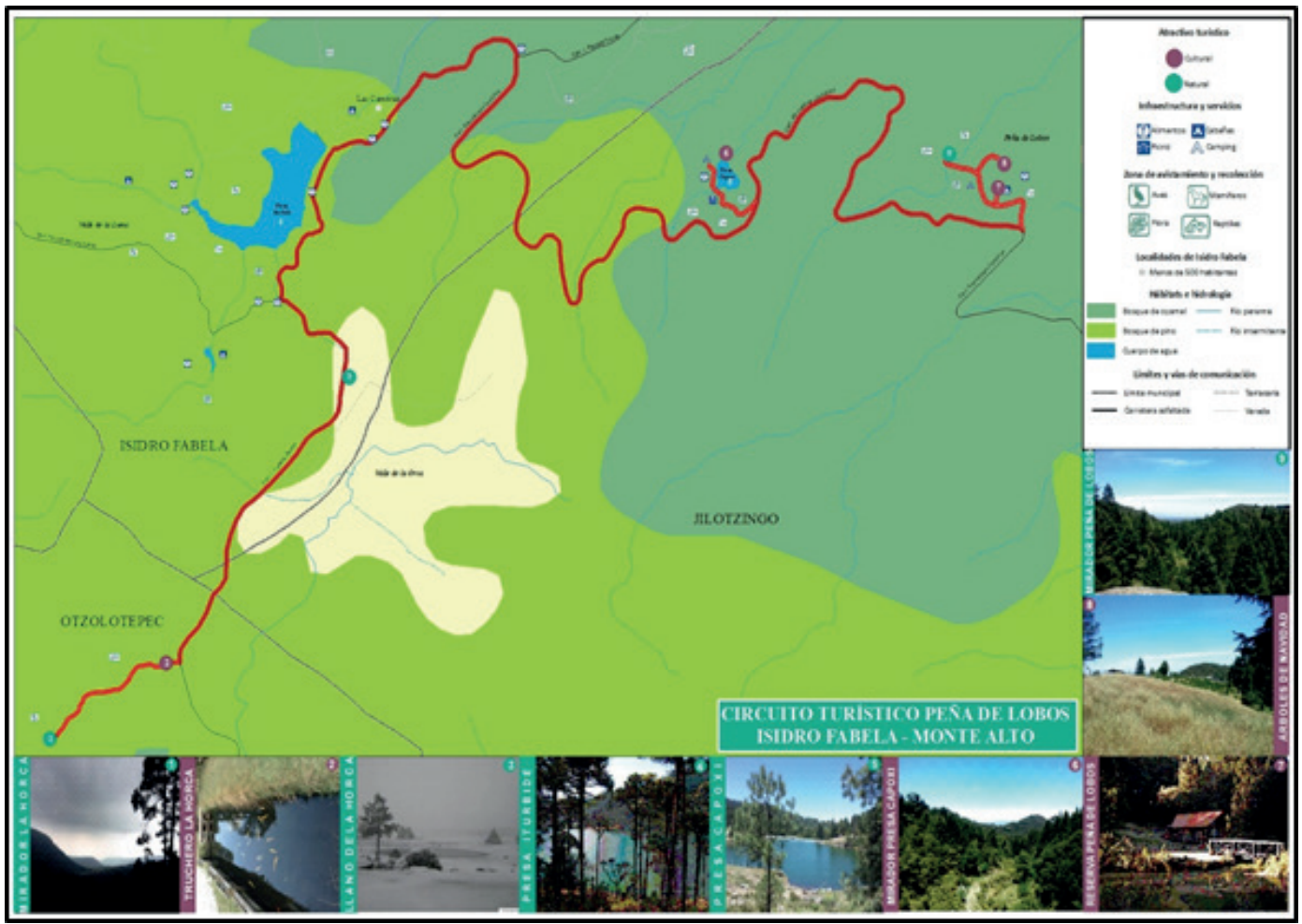

Fuente: Elaboración propia. 
La última perspectiva expresada por los visitantes -segmento poblacional reducido y mínima demanda en el mercado- podría traer como consecuencia un potencial turístico limitado. No obstante, esta postura externa se contrapone a las dimensiones expuestas por Thomé (2008) quien determina que las estrategias diseñadas bajo el marco de estudio del turismo rural, deben estar orientadas hacia segmentos específicos del mercado. Es decir, deben orientarse hacia aquellos turistas que buscan en un territorio, un medio ambiente conservado donde la población local valores sus recursos y conserve el ambiente como precondición para desarrollar estrategias locales de desarrollo sustentable.

Desde los argumentos de este autor, conservación ambiental, valoración local de los recursos y fundamentos teóricos y metodológicos que se consideraron desde la perspectiva local y académica para el diseño e instrumentación de los circuitos, se espera que los visitantes que deseen realizar recorridos por los circuitos compartan la visión local de la conservación, valoración del territorio y los recursos naturales y socioculturales existentes. La viabilidad turística que los visitantes determinan sobre los circuitos es viable pese a estar discernida en dos posturas contradictorias, no obstante, desde el enfoque del desarrollo local y el desarrollo sustentable, ambas posturas sustentan los objetivos teóricos y metodológicos del turismo rural.

Desde los sustentos teóricos y metodológicos del turismo rural y la percepción de los participantes, el recorrido del Circuito Turístico Peña de Lobos es viable y tiene cualidades que pueden detonar un potencial turístico próspero en la región y con ello contribuir de manera positiva al desarrollo local sustentable, ya que una de las preguntas del cuestionario aplicado a los participantes, acerca de cuánto estarían dispuestos a pagar por un recorrido similar, los datos obtenidos expresan que el $60 \%$ de los partícipes pueden pagar entre 150 y 200 pesos mexicanos por persona, mientras, el $40 \%$ solamente está dispuesto a pagar entre 50 y 100 pesos. Considerando un pago promedio por persona de 150 pesos por circuito, con un máximo permitido de 15 personas sugerido en el Manual de Senderos Interpretativos de la SECTUR (2014), entonces, es posible obtener un ingreso económico máximo de $\$ 2,250$ pesos mexicanos, dinero que puede ser aprovechado por los habitantes del municipio que deseen emplearse como guías e intérpretes ambientales.

\section{Discusión y conclusiones}

Al considerar las ideas de los habitantes locales en el diseño e instrumentación de estrategias de desarrollo local sustentable, se rompe el paradigma clásico de la imposición de estrategias de desarrollo, mismas que en muchas ocasiones son formuladas desde una perspectiva externa y rara vez consideran las características biofísicas del territorio, así como las condiciones socioculturales y económicas de la población. Es claro que el objetivo de esta investigación busca romper con el paradigma de la imposición y proponer nuevas estrategias de desarrollo local desde una perspectiva incluyente con base al conocimiento empírico y científico. Al combinar ambos conocimientos se espera que las estrategias de desarrollo local sean sólidas y tengan mayores posibilidades de éxito a largo plazo.

Durante el desarrollo de esta investigación una de las principales confrontaciones que se identificaron durante la selección de la estrategia de desarrollo local sustentable, fueron los diferentes puntos de vista y necesidades de la población local, ya que cada uno de los participantes compartía sus ideas y propuestas desde sus propias necesidades e intereses y no desde una perspectiva colectiva, situación que en su momento provocó dificultades de organización e inquietudes entre los y las participantes, pues cada integrante quería asignarle mayor importancia a sus ideas y opiniones. La oportuna intervención de los integrantes universitarios se orientó principalmente a fortalecer los lazos de cohesión social y reforzar los procesos de colaboración y participación, considerando en todo momento los diferentes puntos de vista de los participantes. Entre el ir y venir del conocimiento empírico y científico se logró unificar las ideas y presentar a los integrantes locales una propuesta clara, precisa y sencilla, en la cual, cada uno de ellos participaría de manera individual y colectiva.

Estas estrategias ayudaron a disolver el sesgo de participación individual, articulando hacia un mismo objetivo los diferentes puntos de vista de los participantes locales. El punto de cohesión identificado durante la selección de estrategias, parte del conocimiento empírico que los habitantes poseen acerca del ambiente, desarrollo sustentable, desarrollo local, desarrollo humano y turismo. Desde estas perspectivas de desarrollo se cimento la idea de crear una serie de circuitos turísticos, a partir de los cuales se articule la participación social entre los habitantes del municipio y el aprovechamiento sustentable del territorio. Sin embargo, para algunos autores como Arriola (2003) y Szmulewicz (s/f) describen a los circuitos turísticos como parte de los atractivos que un territorio puede ofrecer a los visitantes, los 
cuales al momento de su instrumentación puede ocasionar una serie de problemas ambientales y una pérdida de identidad local entre las comunidades receptoras.

Para evitar las problemáticas referidas por Arriola (2003) y Szmulewicz (s/f), el diseño de los circuitos turísticos se sustentó desde dos perspectivas, la primera de ellas cubre las especificaciones ambientales establecidas en el reglamento de la Ley General del Equilibro Ecológico y Protección al Ambiente en Materia de Áreas Naturales Protegidas y el Programa de Manejo del Parque Otomí-Mexica del Estado de México, ya que más del 75\% del territorio municipal esta decretado como ANP. En el área natural protegida existe una zonificación territorial a partir de una serie de políticas de manejo ambiental (protección, conservación, aprovechamiento y restauración), cuyo objetivo es la conservación, preservación, protección y restauración de los ecosistemas locales, además del monitoreo de actividades socioeconómicas permitidas en cada una de zonas que conforman el ANP (LGEEPA-ANP, 2014, CEPANAF, 2016).

Desde la perspectiva jurídica el diseño e instrumentación de los circuitos turísticos cumple con los criterios establecidos en la legislación ambiental mexicana. La segunda perspectiva considerada en el diseño de los circuitos fue la participación social de autoridades y grupos sociales del municipio, esta actividad permitió el fortalecimiento de las estructuras locales y dio paso a la generación de lazos de confianza entre las estructuras locales y externas, mejorando con ello la capacidad de respuesta a las necesidades de desarrollo del territorio y la cohesión social entre los habitantes del municipio.

Chan (1994) concibe a los circuitos turísticos como la base de las visitas guiadas y de los paquetes o programas turísticos, además de enfocar su análisis hacia una perspectiva de comercialización y mercadotecnia en el que destaca a los circuitos como una fuente de creatividad e innovación capaz de permitir a los territorios rurales adaptarse a los movimientos y tendencias de consumo de la demanda, no obstante, es importante mencionar que, al conjugar los criterios establecidos en la legislación ambiental mexicana con las cosmovisiones de las poblaciones locales, se puede establecer que los circuitos turísticos pueden ser más que la base de los programas o paquetes turísticos de un territorio. Se pueden establecer como el eje de encadenamiento entre los habitantes locales y visitantes, generando con ello el desarrollo de sus actividades, lazos de confianza e intercambio de perspectivas sobre la importancia de preservar y aprovechar de manera local y sustentable los componentes ambientales, socioculturales, históricos y turísticos de los ambientes rurales.

Los habitantes locales están conscientes de la importancia de su ambiente y de los beneficios que estos les aportan para su desarrollo humano, económico y cultural, además, consideran de suma importancia que la difusión turística de su territorio debe ser ordenada para evitar los actuales problemas que se experimentan en algunos espacios del territorio. Ejemplo de ello son los procesos de degradación ambiental que se manifiestan en los ambientes que colindan con la Presa Iturbide, principal atractivo turístico del municipio y el lugar donde se realizan actividades de pesca, senderismo, paseo a caballo o en lancha, tirolesa y degustaciones gastronómicas con productos locales.

Desafortunadamente la mala difusión, la poca experiencia de los habitantes en cuestiones turísticas y la escasa conciencia socioambiental de los visitantes, ha traído consigo problemas ambientales como pérdida de especies vegetales, fenómeno que se intensifica durante las festividades decembrinas, ya que muchas de las especies extraídas de manera ilegal por los visitantes y comerciantes de municipios colindantes, son utilizadas para la confección de artesanías y adornos navideños (árbol de navidad y nacimientos), actividades que impactan de manera directa los entornos locales del municipio y aceleran los procesos erosivos del suelo, alteran los ciclos hidrológicos y contribuyen al cambio climático local.

Lo expuesto anteriormente es parte de los procesos de degradación ambiental que se pudieron identificar durante el trabajo de campo y el desarrollo de talleres participativos. Estas actividades permitieron a los participantes establecer que cualquier actividad turística mal planeada puede generar impactos y riesgos negativos a los componentes biofísicos y socioculturales del territorio. En este sentido se espera que los circuitos turísticos sean una estrategia viable para mejorar las condiciones de los ambientes locales, favorecer la continuidad de los procesos ecológicos, fomentar la valoración ambiental del territorio, conservar el patrimonio sociocultural, transitar hacia la sustentabilidad y promover el desarrollo humano.

Se tiene conciencia que el desarrollo de actividades turísticas planeadas puede traer consigo impactos negativos sobre el territorio como: contaminación ambiental, pérdida de biodiversidad, cambios de ocupación de uso del suelo y pérdida de identidad local. Por estas situaciones se recomienda que, antes de iniciar la instrumentación de los circuitos turísticos, se realice un programa de sensibilización ambiental y sociocultural entre los habitantes del municipio, con el propósito de promover acciones que fomenten el cuidado del ambiente, la valorización de la cultura local y garantizar el funcionamiento próspero de los territorios rurales en México. 


\section{Bibliografía}

Arriola, A.

2003. La técnica de crear circuitos turísticos. Lima, Perú: Universidad San Ignacio de Loyola.

Bertrand et al.

1987. "Juazeiro-Petronia; un pole maricher au coer du Sertao", en Rivière, H. (coord.), Portaits de Bahia.

Paris: Eds, de la Maison des Sciences de I 'Homme. Paris, Francia.

Brunhes

1920. Geographie Humaine de la France, Vol. 2: Geographie Politique Et Geographie Du Travail.

Chan, N.

1994. Circuitos turísticos. Programación y cotización. Argentina: Ediciones turísticas. Argentina.

Ceballos, L.

2010. Desarrollo local y sustentabilidad. La percepción de los ejidatarios sobre el manejo forestal en el ejido Atemajac. Universidad de Guadalajara.

CEPANAF. Comisión Estatal de Parques Estatales y de la Fauna

2016. Programa de Conservación del Parque Otomi-Mexica del Estado de México. Gobierno del Estado de México.

CONEVAL. Consejo Nacional de Evaluación de la Política de Desarrollo Social.

2012. Medición de pobreza. Indicadores de pobreza por municipio 2010. Disponible en: http://www. coneval.gob.mx/Medicion/Paginas/Medici\%C3\%B3n/Medición-de-la-pobreza-municipal-2010.aspx

Cooney, P.

2007. Das décadas de neoliberalismo em México: resultados y desafios. Pará, Brasil: Centro Socioeconômico.

Departamento de Economia. Universidade Federal do Pará. Brasil.

FIDA. Fondo Internacional de Desarrollo Agrícola.

2010. El enfoque adaptativo del FIDA relativo a la cartografía participativa. Roma, Italia.

García, E.

1990. Climas de México, 1: 4000 000. IV.4.10 (A). Atlas Nacional de México. Vol. II. Instituto de Geografía, UNAM. México.

García, R.

2006. Sistemas Complejos. Conceptos, métodos y fundamentación epistemológica de la investigación interdisciplinaria. Barcelona, España. Ed. Gedisa.

Garduño, M., Guzmán, C. y Zizumbo, L.

2009. Turismo rural: Participación de las comunidades y programas federales. El Periplo Sustentable. Núm. 17. UAEMex. Estado de México.

Geilfus, F.

2002. 80 herramientas para el desarrollo participativo. IICA. San José, Costa Rica.

INEGI. Instituto Nacional de Estadística y Geografía.

2015. Encuesta Intercensal 2015. Disponible en: http://www.beta.inegi.org.mx/proyectos/enchogares/ especiales/intercensal/

INEGI. Instituto Nacional de Estadística y Geografía.

2015. Continuo de Elevación Mexicano (CEM), versión, 3.0. México. En internet, disponible en: http:// www.inegi.org.mx/geo/contenidos/datosrelieve/continental/Descarga.aspx

INEGI. Instituto Nacional de Estadística y Geografía.

2016. Guía para la interpretación de cartografía uso del suelo y vegetación. Escala 1:250 000. Serie VI. México.

Korstanje, F.

2008. Planeación participativa: herramientas para el desarrollo local en comunidades rurales. Estudios agrarios. Procuraduría agraria.

LGEEPA-ANP.

2014. Reglamento de la ley general del equilibrio ecológico y la protección al ambiente en materia de áreas naturales protegidas. Cámara de diputados del H. Congreso de la unión. México.

Morales, J. y Rocha, J.

2006. Sustentabilidad rural y desarrollo local en el sur de Jalisco. Tlaquepaque: iteso.

OMT. Organización Mundial de Turismo.

2015. Conceptos fundamentales del turismo. Perú. 
Pérez, S.

2010. El valor estratégico del turismo rural como alternativa sostenible de desarrollo territorial rural. Agronomía Colombiana, Vol. 3. Colombia.

Ratzel, F.

1914. Geografia dell'Uomo (Antropogeografia). Torino: Fratelli Bocca Editori. Torino.

Rodríguez, I. 2002. El efecto de las TIC en la organización de la acción colectiva: la virtualización de los movimientos sociales.

Rofman, A. y A. Villar

2006. Desarrollo local. Una revisión crítica del debate. 1a. ed. Buenos Aires, Argentina: Espacio Editorial. SEDESOL. Secretaría de Desarrollo Social.

2013. Unidad de Microrregiones. México, D.F.

SECTUR. Secretaria de Turismo.

2014. Manual de Senderos Interpretativos. México, D.F.

Szmulewicz, P.

s/f. Perspectivas del Turismo Rural. Universidad Austral de Chile. Chile.

Thomé, H.

2008. Turismo rural y campesinado, una aproximación social desde la ecología, la cultura y la economía.

Convergencia. 15 (47): 237-26. Universidad Autónoma del Estado de México. Toluca, México.

Troitiño, M.

2000. Territorio y desarrollo local. J. Cardona Andujar. "Formación y empresa. Ejes del Desarrollo Integral de las Comarcas". Toledo, España: uned/Talavera.

Varisco, C.

2015. Turismo Rural: actores y recursos turísticos. Universidad Nacional de Mar del Plata. Argentina. Vidal, P.

1917. La France de lÉst (Lorraine-Alsace). Présentation dÝves Lacoste, Paris, La Découverte. Pp. 287. Wolfe, A.

1989. Whose keeper. Califórnia: University of California Press, Berkeley, California.

\section{Notas}

Directorio Estadístico Nacional de Unidades Económicas.

Registro Agrario Nacional.

En la columna 7 aparecen dos casillas con valor x, esto se debe a que dentro del recorrido del circuito Laguna Seca y Cerro la Catedral no existe infraestructura o servicios turísticos. 